Journal of Thermal Engineering, Vol. 7, No. 4, pp. 934-950, May, 2021

Yildiz Technical University Press, Istanbul, Turkey

\title{
INFLUENCE OF RELAXATION TIMES ON HEAT TRANSFER IN HUMAN HEAD EXPOSED TO MICROWAVE FREQUENCIES
}

\author{
Jagbir Kaur ${ }^{1, *}$, Suyeb Ahmed Khan²
}

\begin{abstract}
The electromagnetic energy carried by microwaves interacts with human head and produces thermal changes within the head. Conventionally, Pennes' bioheat transfer equation (BTE) is employed to investigate the thermal changes in biological tissues. Pennes' equation assumes infinite speed of propagation of heat transfer, however, heterogeneous structures such as biological tissues exhibit relaxation times, which is the time required for accumulation of enough energy to transfer it to the nearest element. In present study, we utilized thermal wave model of bioheat transfer (TWMBT) which incorporates relaxation times to numerically predict temperature changes in six layers human head. Finite element based numerical simulation package COMSOL Multiphysics ${ }^{\circledR}$ is employed for the thermal analysis. Numerical scheme comprises coupling of solution of Maxwell's equation of wave propagation within tissue to TWMBT. Temperatures estimated with various values of relaxation time are compared with that by Pennes' equation. The results show that the transient temperature within human head estimated with relaxation time $10 \mathrm{~s}, 20 \mathrm{~s}$, and $30 \mathrm{~s}$ can be up to $36 \%, 54 \%$, and $66 \%$ lower than predicted by Pennes' BTE respectively. At longer microwave exposure the influence of relaxation times becomes insignificant and the steady state temperatures predicted by TWMBT and Pennes' BTE are identical. The findings suggest that inclusion of relaxation times in thermal analysis is of significant importance if the exposure duration is short. The effect of parameters such as microwave power and user age on the temperatures projected with different relaxation times is also investigated.
\end{abstract}

Keywords: Bioheat Transfer, Thermal Wave Model of Bioheat Transfer (TWMBT), Human Head, Microwaves, Relaxation Time

\section{INTRODUCTION}

Microwaves are utilized in a number of applications including wireless communication, mobile phones, Magnetic Resonance Imaging (MRI) machines, RADAR, navigation equipment and drying and heating industry [13]. The rapid advancement of microwave applications has caused a public concern about its biological safety. The electromagnetic (EM) energy associated with microwaves can interact with the biological tissues, and the resulting biological effects depend upon intensity, frequency, waveform and duration of exposure [4]. This energy is transferred to the biological medium which produces ion acceleration and collisions among molecules and the local temperature of the tissue rises [5]. An increase of $1-5^{\circ} \mathrm{C}$ in human body can cause many malformations including male infertility, brain lesions, and blood chemistry changes [6]. Even a very small temperature change of $0.2-0.3^{\circ} \mathrm{C}$ in hypothalamus may cause altered thermoregulatory responses [7]. Considering the hazards of temperature rise in biological tissues, it is important to investigate the thermal alterations in the sensitive organ such as brain caused by microwave exposure.

The heat generation in human head due to exposure to electromagnetic fields has been a topic of interest and concern among the researchers for many years. Kargel has measured the temperature rise in ear- skull region caused by $1800 \mathrm{MHz}$ GSM mobile phones using infrared thermal imaging [8]. Kodera et al. have studied the thermal changes in human head due to exposure to gigahertz frequencies [9]. Many studies have employed Pennes' bioheat transfer equation (BTE) to investigate the temperature change in human head [10-14]. Ibrahiem et al. [10] and Bernardi et al. [11] have numerically studied the temperature rise in human head exposed to $900 \mathrm{MHz}$ radiation. Leeuwen et al. [12] and Wang and Fujiwara [13] have used Finite Difference Time Domain (FDTD) model to This paper was recommended for publication in revised form by Assigned Editor Baha Zafer

${ }^{\prime *}$ Research Scholar, Department of Research and Development, I.K. Gujral Punjab Technical University, Jalandhar, Punjab, India.

${ }^{2}$ Shiv Shankar Institute of Engineering and Technology, Patti, Tarn taran, Punjab, India.

${ }^{*}$ Corresponding author's E-mail address: jagbirk@gmail.com*

Orcid id: 0000-0001-9937-0084, 0000-0001-8565-5134

Manuscript Received 10 May 2019, Accepted 23 September 2019 
predict the thermal changes in head caused by a dipole antenna at $915 \mathrm{MHz}$ and $1.5 \mathrm{GHz}$ respectively. Wessapan et al. [14] have numerically analyzed thermal changes in 3-dimensional human head at different frequencies. However, Pennes' BTE assumes that the thermal wave propagates with infinite speed inside the tissue, and any thermal disturbance in the tissue is instantaneously felt by the body $[15,16]$. On the other hand, in heterogeneous biological media such as human body, a relaxation time $(\tau)$ is required for accumulation of enough energy to transfer it to the nearest element $[17,18]$. Thermal wave model of bioheat transfer (TWMBT) incorporates relaxation time to account for the lag time it takes for the EM wave to respond to heat propagation through biological tissue [19, 20]. Xu et al. [21] examined heat transfer in skin tissue with relaxation time range $0-15 \mathrm{~s}$, while some experimental studies have shown that relaxation time ranges from 15 to 30s [22-25]. Kaur and Khan [26] studied the effect of relaxation times on the temperature variations in human abdomen due to microwave exposure at $2450 \mathrm{MHz}$ with various values of microwave powers. Many studies have employed TWMBT to determine the risk that electromagnetic radiation pose when skin tissues are exposed to them [15, 22-25,27], however, studies reporting effects of relaxation times on heat transfer in head are limited. To best of our knowledge only Tullius and Bayazitoglu [28] have included relaxation times in their analysis to estimate the thermal changes in human head exposed to microwaves. They have concluded that higher relaxation times predict greater temperature rise in the tissue which is contrary to the thermal changes predicted by Ozen et al.[16], Liu et al. [17], Jing Liu et al. [19], Ahmadikia et al.[20] and Liu et al.[27]. Later studies have demonstrated that the temperature predicted with higher relaxation time is lower. Therefore, the effect of relaxation times on temperature variations within human head due to microwave exposure is ambiguous. More studies are needed to be conducted to understand the effect of relaxation times on temperature variations within human head caused by microwave exposure. With this background, the present study is aimed to evaluate the effect of relaxation times on the temperature variations within human head exposed to microwaves.

In the present study, we have used Finite Element Method (FEM) to numerically analyze the thermal changes in a six layers model of human head exposed to microwave frequencies. The frequencies employed in MRI machine, mobile communication systems, wireless communications etc. viz. $300 \mathrm{MHz}, 900 \mathrm{MHz}, 1800 \mathrm{MHz}$ and $2450 \mathrm{MHz}$ are considered in analysis [1]. We have employed TWMBT with different relaxation times $(0-30 \mathrm{~s})$ to estimate the temperature rise in human head. While studying the effect of relaxation times on heat transfer, parameters such as power of incident microwaves and user age are also considered.

\section{MATHEMATICAL MODEL}

Pennes' BTE is the most commonly used for analyzing heat conduction in biological tissues [29]. In two dimensional form, the equation can be expressed as:

$\rho C \frac{\partial T(x, y, t)}{\partial t}=\nabla .(K \nabla T(x, y, t))+\rho_{b} C_{b} \omega_{b}\left(T_{b}-T(x, y, t)\right)+Q_{m}(x, y, t)+Q_{\text {ext }}(x, y, t)$

where, $\nabla=\left[\frac{\partial}{\partial x}, \frac{\partial}{\partial y}\right] . \rho, \mathrm{C}$ and $K$ are the density $\left(\mathrm{kg} / \mathrm{m}^{3}\right)$, specific heat at constant pressure $(\mathrm{J} / \mathrm{kg} . \mathrm{K})$, and the thermal conductivity (W/m.K) of tissue, respectively. $\rho_{b}$ and $C_{b}$ are the density $\left(\mathrm{kg} / \mathrm{m}^{3}\right)$ and specific heat $(\mathrm{J} / \mathrm{kg} . \mathrm{K})$ of the blood at constant pressure, respectively. $\omega_{b}$ is the blood perfusion rate $(1 / \mathrm{s}) ; T(x, y, t)$ and $T_{b}$ are tissue and blood temperatures $\left({ }^{\circ} \mathrm{C}\right)$, respectively. $Q_{m}(x, y, t)$ is metabolic heat generation in the tissue $\left(\mathrm{W} / \mathrm{m}^{3}\right)$ and $Q_{\text {ext }}(x, y, t)$ is the external heat source term (electromagnetic heat-source density) $\left(\mathrm{W} / \mathrm{m}^{3}\right)$. The term $\nabla .(K \nabla T(x, y, t))$ in Eq.(1) represents the heat conduction inside the human head and is based on Fourier's law [21]:

$$
q(x, y, t)=-K \nabla T(x, y, t)
$$

This law implies that any thermal disturbance is instantaneous within the tissue [21]. The term $\rho_{b} C_{b} \omega_{b}\left(T_{b}-T(x, y, t)\right)$ describes the heat caused by convection inside the biological medium. $Q_{\text {ext }}$ represents the resistive heat generated by the electromagnetic source and is expressed as [14]: 


$$
Q_{\text {ext }}=\frac{1}{2} \sigma|E(x, y, t)|^{2}
$$

where $\sigma$ is the conductivity $(\mathrm{S} / \mathrm{m})$ of the tissue and $E(x, y, t)$ is the electric field $(\mathrm{V} / \mathrm{m})$ within the tissue exposed to microwaves.

Fourier's law defined by Eq. (2) successfully explains the heat conduction in homogeneous materials [30]. However, non-homogeneous structures such as biological mediums exhibit a higher microscale thermal response [31,32]. Therefore, a non-Fourier model should be considered for heat propagation in biological tissues. The concept of thermal lag is formulated in the Fourier's law with addition of relaxation time ' $\tau$ ' in Eq. (2) as [33-34]:

$$
q(x, y, t+\tau)=-K \nabla T(x, y, t)
$$

where $\tau=\alpha / C_{t}^{2}$ is defined as the thermal relaxation time with $\alpha$ being the thermal diffusivity $\left(\mathrm{m}^{2} / \mathrm{s}\right)$, and $\mathrm{C}_{\mathrm{t}}$ being the speed of thermal wave in the medium (m/s). Substituting the first order Taylor expansion of Eq. (4) in Eq. (1), a new TWMBT is obtained [18]:

$\rho C \tau \frac{\partial^{2} T(x, y, t)}{\partial t^{2}}=K \nabla^{2} T(x, y, t)-\rho_{b} C_{b} \omega_{b} T(x, y, t)-\left(\tau \rho_{b} C_{b} \omega_{b}+\rho C\right) \frac{\partial T(x, y, t)}{\partial t}+\rho_{b} C_{b} \omega_{b} T_{b}+$

$Q_{m}(x, y, t)+Q_{\text {ext }}(x, y, t)+\tau \frac{\partial Q_{m}(x, y, t)}{\partial t}+\tau \frac{\partial Q_{e x t}(x, y, t)}{\partial t}$

$\nabla=\left[\frac{\partial}{\partial x}, \frac{\partial}{\partial y}\right], \nabla^{2}=\left[\frac{\partial^{2}}{\partial x^{2}}, \frac{\partial^{2}}{\partial y^{2}}\right]$

$Q_{m}(\mathrm{x}, \mathrm{y}, \mathrm{t})$ is neglected and assumed zero in the analysis, since we aim to evaluate the effect of electromagnetic energy associated with microwaves only. Hence, Eq. (5) can be re-written as:

$\rho C \tau \frac{\partial^{2} T(x, y, t)}{\partial t^{2}}=K \nabla^{2} T(x, y, t)-\rho_{b} C_{b} \omega_{b} T(x, y, t)-\left(\tau \rho_{b} C_{b} \omega_{b}+\rho C\right) \frac{\partial T(x, y, t)}{\partial t}+\rho_{b} C_{b} \omega_{b} T_{b}+$

$Q_{e x t}(x, y, t)+\tau \frac{\partial Q_{e x t}(x, y, t)}{\partial t}$

It should be noted that if relaxation time is zero $(\tau=0 \mathrm{~s})$ in Eq. (6), it transforms to Eq. (1). This implies, for relaxation time equals zero, TWMBT predicts the same temperature as Pennes' BTE. Hence, Pennes' BTE can be considered special case of TWMBT.

\section{NUMERICAL METHOD}

A six layers human head model used by Sabbah et al. [35] is employed for numerical simulation. The head model comprises skin, fat, bone, dura, CSF and brain as shown in Fig. 1. The thickness of various layers in head is same as in the head model described in [35]. The microwave source is placed $2 \mathrm{~cm}$ away from the exposed surface. The dielectric properties of head layers at different frequencies and their thermal properties are listed in Table 1 and Table 2 respectively. The dielectric properties of brain are obtained by averaging the properties of white and gray brain matter. The head model is exposed to transverse magnetic (TM mode) plane microwaves propagating along Xaxis with radiated power of $1 \mathrm{~W}$. Radiated power used in our analysis lies within ICNIRP safety limits at the maximum specific absorption rate (SAR) of $2 \mathrm{~W} / \mathrm{kg}$ [36]. Numerical analysis is performed using FEM based simulation software COMSOL Multiphysics ${ }^{\circledR}$, since FEM models provide quick and accurate solution for the system of multiple differential equations [37]. Previously, many studies have employed COMSOL Multiphysics ${ }^{\circledR}$ to investigate the heat transfer in biological tissues [14, 38, 40-42].

The investigation is executed in two steps, i.e. electromagnetic analysis and bioheat transfer analysis within the head model. 


\section{Electromagnetic Analysis}

Exposure to microwaves causes generation of electric field within the head. The electric field is mapped inside the tissues in electromagnetic analysis. Some assumptions are made for simplification of the problem:

1. The electromagnetic wave propagation is modeled in 2-dimensions.

2. The interaction between microwaves and the human head takes place in open region i.e. the head model is not surrounded by walls, metallic encasing etc.

3. The microwaves are plane waves (TM mode) travelling along positive X-axis.

4. The dielectric properties of tissues are uniform and constant for each layer.

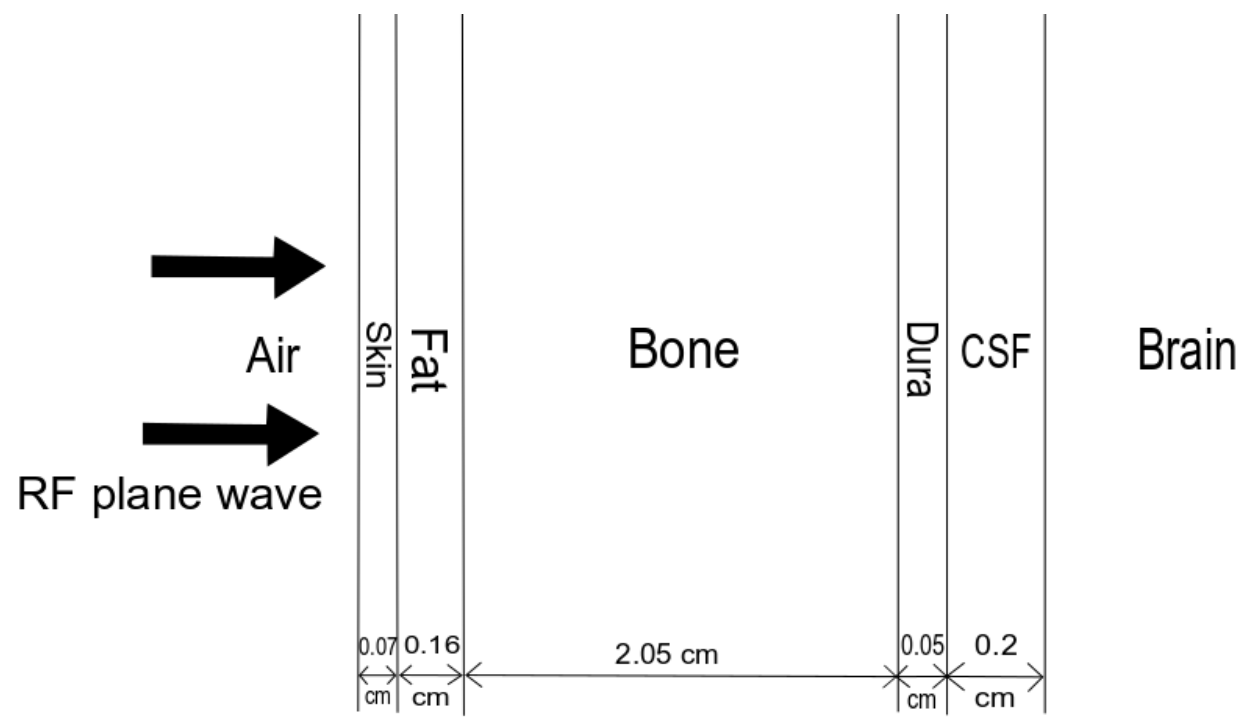

Figure 1. Six layers human head model

Table 1. Dielectric properties of head layers at different frequencies [39]

\begin{tabular}{|l|c|c|c|c|c|c|c|c|}
\hline & \multicolumn{2}{|c|}{$300 \mathrm{MHz}$} & \multicolumn{2}{c|}{$900 \mathrm{MHz}$} & \multicolumn{2}{c|}{$1800 \mathrm{MHz}$} & \multicolumn{2}{c|}{$2450 \mathrm{MHz}$} \\
\hline \multirow{2}{*}{ Skin } & $\varepsilon_{\mathrm{r}}$ & $\sigma(\mathrm{S} / \mathrm{m})$ & $\varepsilon_{\mathrm{r}}$ & $\sigma(\mathrm{S} / \mathrm{m})$ & $\varepsilon_{\mathrm{r}}$ & $\sigma(\mathrm{S} / \mathrm{m})$ & $\varepsilon_{\mathrm{r}}$ & $\sigma(\mathrm{S} / \mathrm{m})$ \\
\hline Fat & 49.8 & 0.641 & 41.4 & 0.867 & 38.9 & 1.18 & 38.1 & 1.46 \\
\hline Bone & 5.63 & 0.039 & 5.46 & 0.051 & 5.34 & 0.078 & 5.28 & 0.105 \\
\hline Dura & 13.4 & 0.083 & 12.5 & 0.143 & 11.8 & 0.28 & 11.4 & 0.394 \\
\hline CSF & 72.7 & 0.804 & 44.4 & 0.961 & 42.9 & 1.32 & 42.0 & 1.67 \\
\hline Brain & 51.9 & 0.552 & 45.8 & 0.77 & 43.5 & 1.15 & 42.6 & 1.48 \\
\hline
\end{tabular}

Maxwell's equations govern the propagation of electromagnetic waves inside the human body and electric field intensity $(\mathrm{E})$ can be determined by equation $[14,38]$ :

$$
\nabla \times \frac{1}{\mu_{r}}(\nabla \times E(x, y, t))-k_{0}^{2}\left(\varepsilon_{r}-\frac{j \sigma}{\omega \varepsilon_{0}}\right) E(x, y, t)=0
$$


where $\nabla=\left[\frac{\partial}{\partial x}, \frac{\partial}{\partial y}\right], \mu_{r}$ is relative magnetic permeability, $\varepsilon_{r}$ is relative permittivity, $\varepsilon_{0}=8.8542 \times 10^{-12} \mathrm{~F} / \mathrm{m}, k_{0}$ is the free space wave number $(1 / \mathrm{m})$ and $\omega$ is angular frequency $(\mathrm{Hz})$. Using the value of electric field at a point within head, the heat generated due to EM energy associated with microwaves is calculated at that point by utilizing Eq. (3). In electromagnetic analysis, scattering boundary condition is applied on outer edges of the calculated domain (Fig. 2), as [14, 40]:

$$
n \times(\nabla \times E(x, y, t))-j k n \times(E(x, y, t) \times n)=-n \times\left(E_{0}(x, y, t) \times j k(n-k)\right) \exp (-j k . r(x, y))
$$

where $\nabla=\left[\frac{\partial}{\partial x}, \frac{\partial}{\partial y}\right], k$ is the wave number $(1 / \mathrm{m}), \mathrm{n}$ is normal vector, $j=\sqrt{-1}$, and $E_{0}(x, y, t)$ is incident plane wave $(\mathrm{V} / \mathrm{m})$

A microwave device emits EM energy with specific power. The output port of such a device is characterized by wave port. The stimulator employs wave port boundary condition on left side of head model. The plane microwaves in transverse magnetic (TM) mode emitted by wave port fall on this side of the head. The wave port boundary condition is described by [40]:

$S=\int\left(\left(E(x, y, t)-E_{1}(x, y, t)\right) \cdot E_{1}(x, y, t)\right) d A_{1} / \int\left(E_{1}(x, y, t) \cdot E_{1}(x, y, t)\right) d A_{1}$

where $E(x, y, t)$ is the electric field intensity $(V / m)$, and $E_{1}(x, y, t)$ is fundamental value of electric field for the wave port.

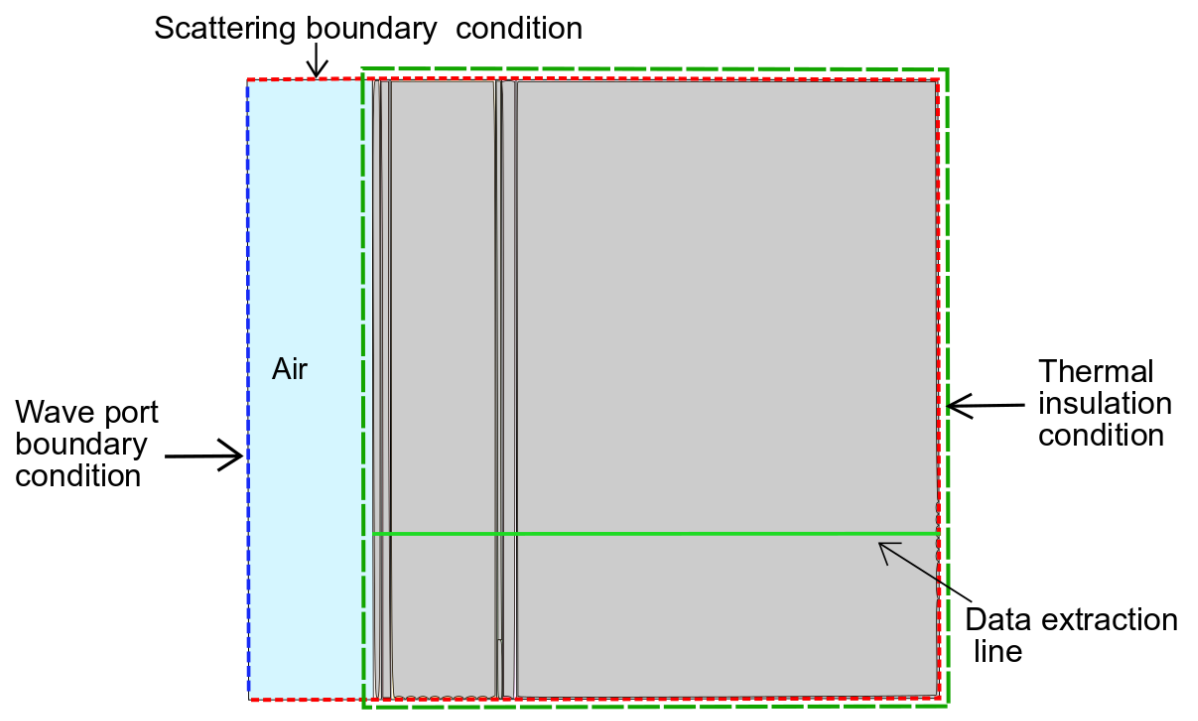

Figure 2. Boundary conditions for numerical analysis and data extraction line (arc length) at which temperature variations are considered

\section{Bioheat Analysis}

Thermal changes within the head model are investigated by coupling the bioheat model with the EM wave propagation equations. Using Eq. (7), the electric field distribution within the calculated domain is obtained. The heat generated in the tissue due to electromagnetic energy $\left(Q_{e x t}\right)$ is calculated by employing Eq. (3). TWMBT (Eq. (6)) is utilized to investigate the heat transfer within the human head and to evaluate the effect of relaxation times on temperature changes within the tissues. 
To solve the thermal problem some assumptions are made:

1. The head layers are considered biomaterials with constant properties for each layer.

2. The metabolic heat and thermoregulation are neglected in the analysis.

3. The head model is thermally insulated.

4. No chemical reaction takes place within the head model.

5. There is no phase change of substance within the model.

Eq. (6) is the coefficient form partial differential equation (PDE) of the TWMBT used for temperature analysis. This PDE is directly employed in same form in COMSOL Multiphysics ${ }^{\circledR}$ simulation software for investigating the thermal changes in the head model.

In bioheat analysis, tissues are assumed to have uniform initial temperature of $37^{\circ} \mathrm{C}[27,42]$. The initial temperature conditions can be described as:

$$
\mathrm{T}(\mathrm{x}, \mathrm{y}, \mathrm{t})=37^{\circ} \mathrm{C} \text {, at } \mathrm{t}=0 \text { and } \frac{\partial T(x, y, t)}{\partial t}=0 \text { at } \mathrm{t}=0
$$

The head model is thermally insulated i.e. there is no heat exchange between head tissues and the surroundings. Thermal insulation boundary condition is applied on the outer edges of calculated domain as [14]:

$$
\text { n. }(K \nabla T(x, y, t))=0
$$

Table 2. Thermal and physical properties of human head [14, 39]

\begin{tabular}{|c|c|c|c|c|}
\hline & $\begin{array}{c}\text { Thermal } \\
\text { conductivity, } \mathrm{K} \\
\left(\mathrm{W} \mathrm{m}^{-1} \mathrm{~K}^{-1}\right)\end{array}$ & $\begin{array}{c}\text { Specific heat, } \mathrm{C} \\
\left(\mathrm{J} \mathrm{kg}^{-1} \mathrm{~K}^{-1}\right)\end{array}$ & $\begin{array}{c}\text { Density, } \rho \\
\left(\mathrm{kg} \mathrm{m}^{-3}\right)\end{array}$ & $\begin{array}{c}\text { Blood perfusion } \\
\text { rate, } \omega_{\mathrm{b}}\left(\mathrm{s}^{-1}\right)\end{array}$ \\
\hline Skin & 0.42 & 3600 & 1125 & 0.02 \\
\hline Fat & 0.25 & 3000 & 916 & $4.58^{*} 10^{-4}$ \\
\hline Bone & 0.39 & 3100 & 1850 & $4.36^{*} 10^{-4}$ \\
\hline Dura & 0.5 & 3600 & 1125 & $6.63 * 10^{-3}$ \\
\hline CSF & 0.62 & 4000 & 1007.2 & 0 \\
\hline Brain & 0.535 & 3650 & 1038 & $8.83 * 10^{-3}$ \\
\hline Blood & 0.52 & 3960 & 1050 & -- \\
\hline
\end{tabular}

\section{Grid Independence}

A grid independence test is performed to ensure that the results of numerical simulation are independent of the number of elements of grid. The number of grid elements, into which the calculated domain is discretized, is successively increased and maximum steady temperature in the brain is recorded at $900 \mathrm{MHz}$. Fig. 3(a) shows dependence of maximum steady state brain temperature on number of grid elements. The temperature doesn't vary above number of elements more than 12000. Thus, the grid independence is attained for the number of elements more than 12000. In our simulation the number of elements is 32437 , which is fairly higher than the number of elements at which grid independence is attained. Therefore, the simulation results are independent of the number of grid elements. 


\section{RESULTS}

The thermal variations within the human head exposed to microwave frequencies are investigated by utilizing the TWMBT. Various frequencies included in analysis are $300 \mathrm{MHz}, 900 \mathrm{MHz}, 1800 \mathrm{MHz}$ and $2450 \mathrm{MHz}$. The study emphasizes on the role of thermal relaxation times on the temperature changes. The values of relaxation time selected in our analysis are $0 \mathrm{~s}, 10 \mathrm{~s}, 20 \mathrm{~s}$, and $30 \mathrm{~s}$.

\section{Validation}

Measuring the temperature distribution directly inside human head to validate the numerical solution is not possible due to ethical considerations. To validate the accuracy of numerical simulation, it is required to reproduce the results of a previous research study using our simulation method. In order to ensure the accuracy of our simulation we have reproduced the results reported by Leeuwen et al. [12] employing simulation used in present study. Leeuwen et al. [12] studied thermal changes in 3-Dimensional human head model obtained by magnetic resonance angiography scans. The head model was exposed to $915 \mathrm{MHz}$ microwaves emitted by half wavelength dipole antenna placed at a distance of $2 \mathrm{~cm}$ away from the head surface. The antenna emitted an average power of $0.25 \mathrm{~W}$. In order to validate numerical simulation used in present study, we conducted the validation test with the exposure parameters same as by Leeuwen et al. [12]. We compared the peak temperature in CSF/brain with that reported by Leeuwen et al. [12]. We have used TWMBT with $\tau=0 \mathrm{~s}$, since TWMBT with $\tau=0 \mathrm{~s}$ gives same results as Pennes' bioheat equation (as used in [12]). Fig. 3(b) compares the peak temperature changes in CSF/ brain in normal head at $915 \mathrm{MHz}$ reported by Leeuwen and obtained by present simulation. The favorable comparison of results confirms the accuracy of the simulation used. The deviation between two curves may be due to different simulation techniques employed in two studies or geometries of the head model.

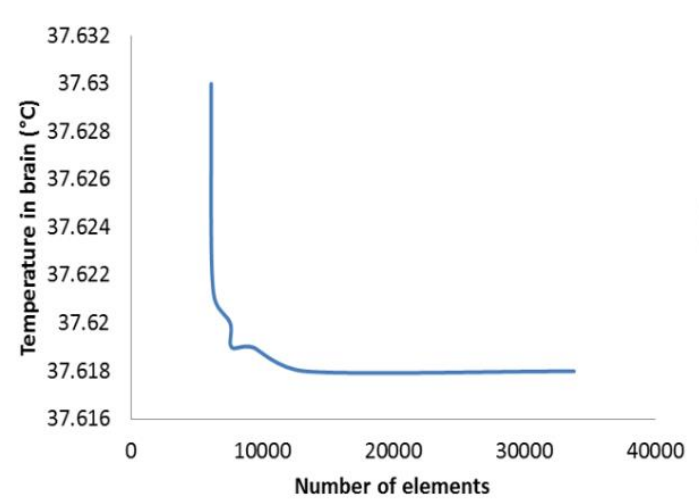

a)

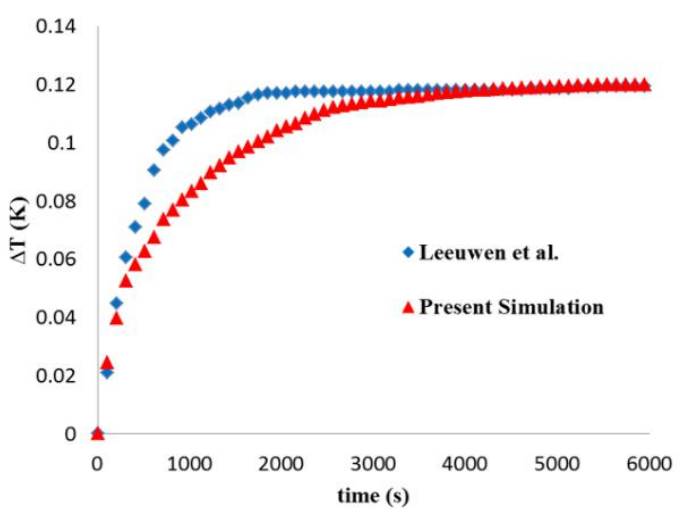

b)

Figure 3. (a) Grid independence for FEM analysis (b) Comparison of peak temperature changes in human brain calculated by present numerical simulation and that by Leeuwen et al. [12]

\section{Thermal Changes and Influence of Relaxation Times}

Fig. 4 shows the temperature distribution within the human head at 1 minute of microwave exposure for 900 and $2450 \mathrm{MHz}$ predicted with relaxation time, $\tau=0$. The hotspots occur at corners of the considered domain, where maximum temperature rise $\left(37.39{ }^{\circ} \mathrm{C}\right.$ at $900 \mathrm{MHz}$ and $37.074{ }^{\circ} \mathrm{C}$ at $\left.2450 \mathrm{MHz}\right)$ is observed. The abrupt geometry changes may be the reason for creation of these high temperature regions. These hotspots may be ignored in the analysis as no such abrupt geometrical changes are there in actual human skull. 
Journal of Thermal Engineering, Research Article, Vol. 7, No. 4, pp. 934-950, May, 2021

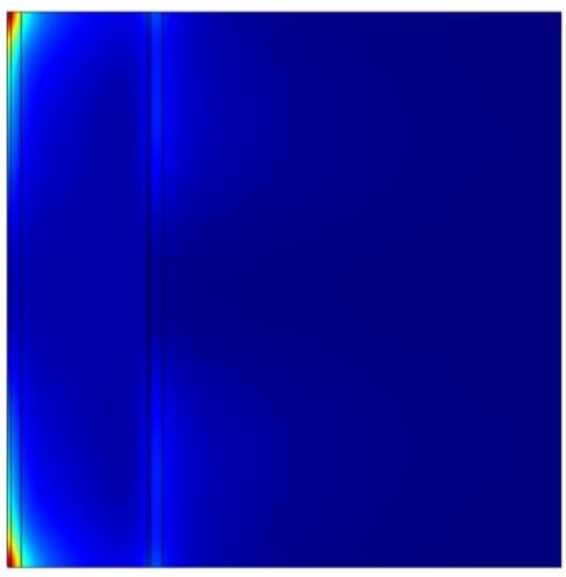

$900 \mathrm{MHz}$

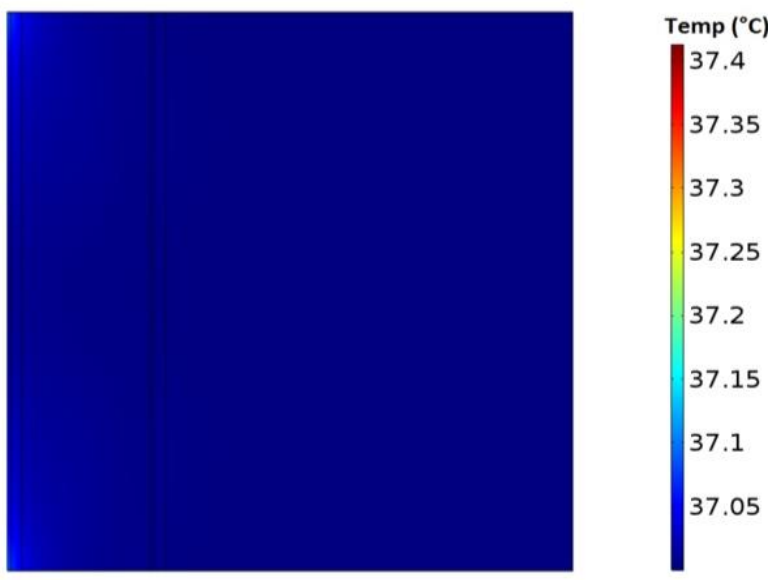

$2450 \mathrm{MHz}$

Figure 4. Temperature distribution in the head model at 1 minute of exposure for $900 \mathrm{MHz}$ and $2450 \mathrm{MHz}$

Thermal changes in human head due to microwave exposure are analyzed using TWMBT with different values of relaxation time. Fig. 5 predicts the temperature variations at 1 minute of microwave exposure along data extraction line, arc length (Fig. 2), running through different layers of human head. Fig. 5 shows that at all the exposure frequencies, the predicted temperature decreases with increasing relaxation time. $\tau=0$ s prophesies the highest temperature in the human head, whereas, $\tau=30 \mathrm{~s}$ estimates the lowest temperature curve. This finding is in agreement with the results in previous studies [16, 17, 19, and 20]. It should also be noted, that temperature predicted with $\tau=0 \mathrm{~s}$ is same as by Pennes' BTE. Since Pennes' BTE has been widely employed to estimate the temperature rise in human head, the actual temperature rise may be lower than predicted using Pennes' BTE in previous studies.

Fig. 5 conveys that the highest temperatures in all the exposure cases are estimated in skin layer of human head. The difference between the temperatures predicted with different relaxation times is largest in skin layer. Another temperature peak is observed in the CSF layer of brain, no blood perfusion in CSF can be held responsible for this behavior of temperature (Table 2). Since there is no blood flow the CSF layer, the heat is not swept away by the blood away from the exposed tissue. As the distance from the exposed surface increases, the difference in temperature curves decreases and the curves almost merge deep in brain. Therefore, temperatures predicted using various relaxation time values are same in core of the brain, but the skin temperatures vary significantly. 


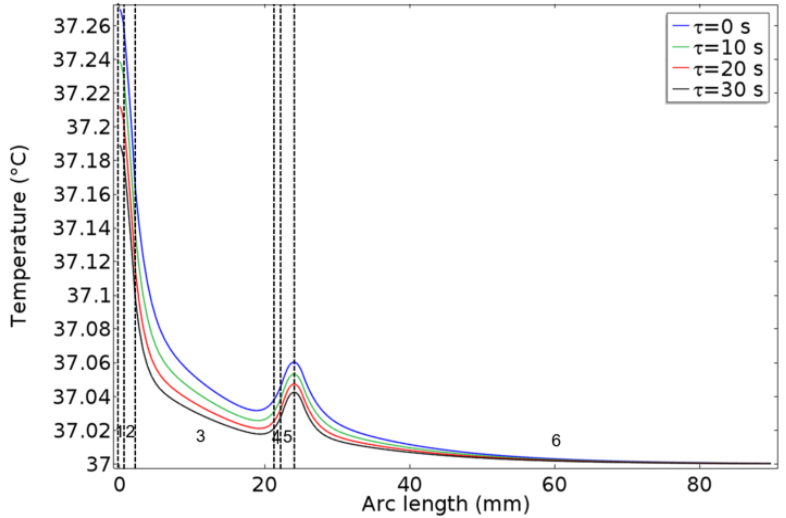

a)

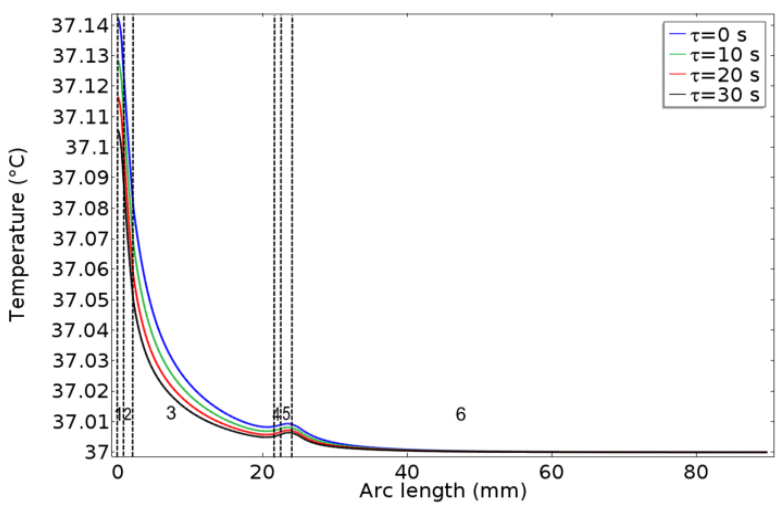

c)

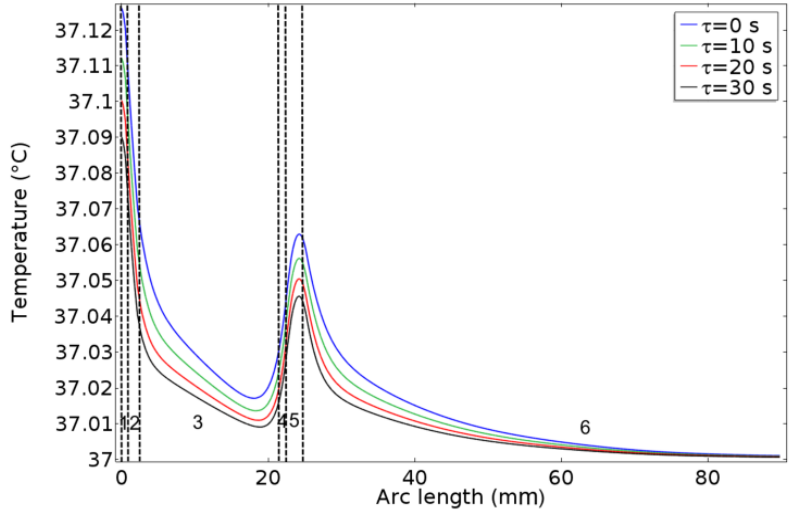

b)

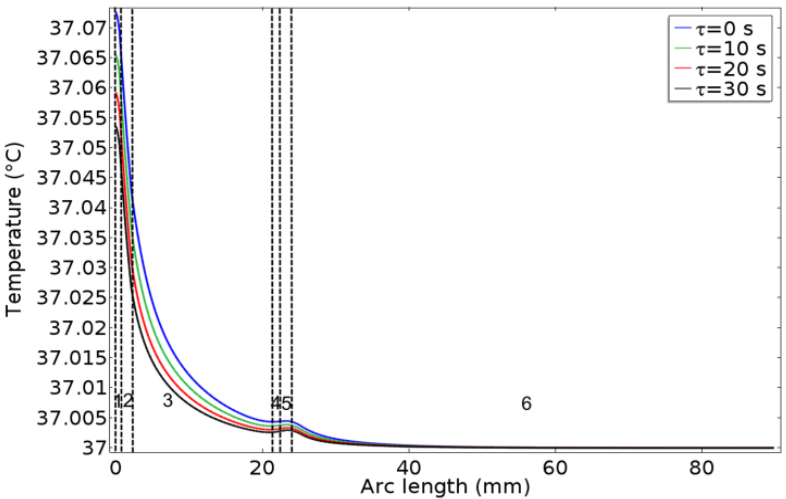

d)

Figure 5. Temperature versus arc length at 1 minute of exposure for different microwave frequencies a) $300 \mathrm{MHz}$, b) $900 \mathrm{MHz}$, c) $1800 \mathrm{MHz}$ and d) $2450 \mathrm{MHz}$. 1: skin, 2: fat, 3: bone, 4: dura, 5: CSF, 6: brain

Fig. 5 also shows that the temperature rise is more significant at lower frequencies; at $300 \mathrm{MHz}$ temperature change is the greatest among all the frequencies. At higher frequencies the temperature change is too small to cause any thermal damage to head tissues. Therefore, they may be considered "thermally safe".

Fig. 6 compares the temperature changes in head layers for different relaxation times at all the exposure frequencies at $30 \mathrm{~s}$ of exposure. In all the exposure cases, the highest temperature change predicted with $\tau=10 \mathrm{~s}$ in skin, fat, bone, dura, CSF and brain is 20-25\%, 25\%, 33\%, 25-28\%, 20-27\% and 30-36\% lower than the temperature change predicted with $\tau=0 \mathrm{~s}$, respectively. TWMBT with $\tau=0 \mathrm{~s}$ estimates the temperature changes same as Pennes' BTE. The change in temperature with $\tau=20 \mathrm{~s}$ for all frequencies in skin, fat, bone, dura, CSF and brain is $34-40 \%, 43-45 \%, 51-54 \%$, 40-44\%, 35-45\% and 50-54\% lower than thermal changes predicted by Pennes' BTE, respectively. And with relaxation time, $\tau=30 \mathrm{~s}$, the temperature changes are $45-50 \%, 53-57 \%, 62-66 \%, 52-56 \%$, 46-54\%, and 60-66\% lower than Pennes' BTE in skin, fat, bone, dura, CSF and brain, respectively. This implies that the transient temperature variations predicted by TWMBT with different relaxation times are significantly different than those by Pennes' BTE. The relaxation times play important role in accurate estimation of thermal changes in head tissues due to exposure to microwaves. With $\tau=10 \mathrm{~s}$, the temperature change is up to $36 \%$ lower than predicted conventionally. While with $\tau=20 \mathrm{~s}$ and $\tau=30 \mathrm{~s}$ temperature change predicted is up to $54 \%$ and $66 \%$ lower than by conventional Pennes' BTE, respectively. 


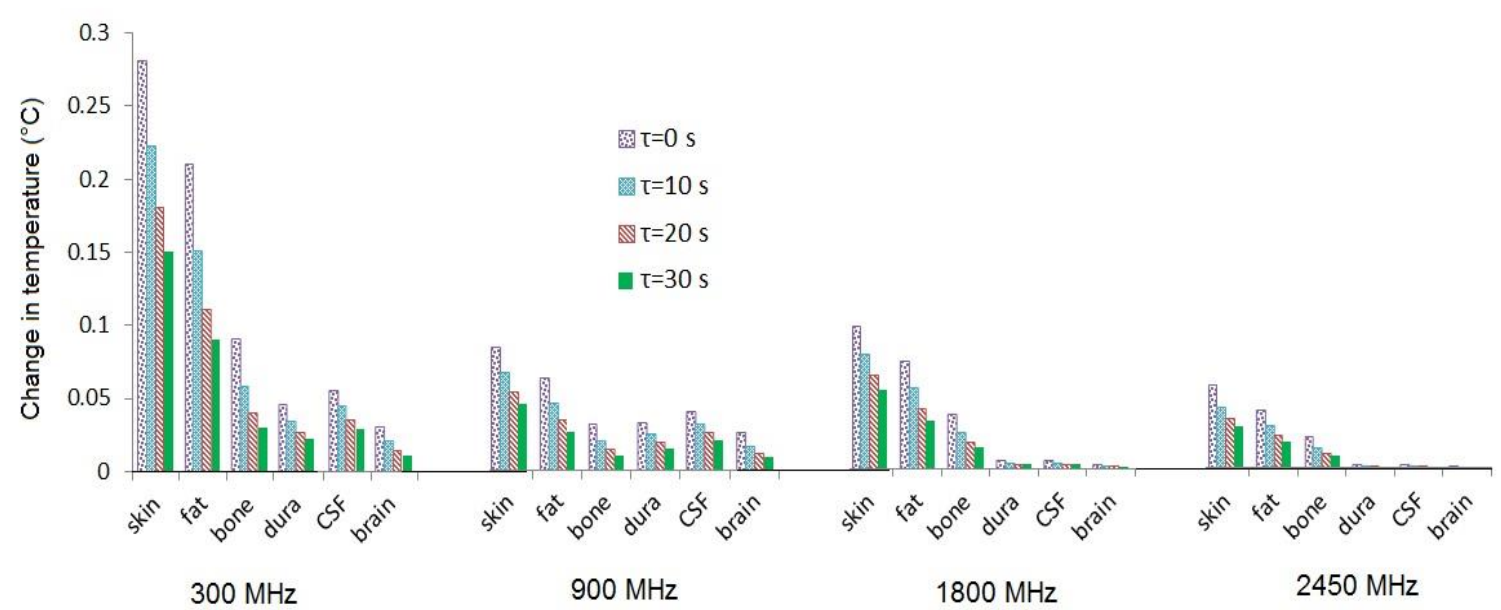

Figure 6. Comparison of temperature changes in various head layers for different relaxation times at $30 \mathrm{~s}$ of microwave exposure

Fig. 7 depicts the influence of relaxation times on temperature at longer exposure durations. The temperature curves are estimated at 5 minutes and 30 minutes of microwave exposure. The temperature curves are closer to each other at 5 minutes of exposure than at 1 minute, and at 30 minutes of exposure they almost merge together. This finding conveys that TWMBT with different relaxation times predicts distinct temperatures than Pennes' BTE only if the exposure duration is short. For longer exposure durations, temperatures predicted by both the models are almost identical. Influence of relaxation times is significant only when calculating transient temperatures, the steady state temperatures show trivial changes with relaxation times.

To evaluate the dependence of temperature predicted with various relaxation times on power of microwaves, we analyzed the thermal changes in head at $900 \mathrm{MHz}$ for 1 minute of exposure at two microwave powers viz. $1 \mathrm{~W}$ and $2 \mathrm{~W}$. Fig. 8 demonstrates the effect of microwave power on the temperature predicted with various values of relaxation times. It shows that at $2 \mathrm{~W}$, temperature change predicted is $100 \%$ higher than that at $1 \mathrm{~W}$. At $2 \mathrm{~W}$, the temperature change in skin estimated by Pennes' BTE is $0.251{ }^{\circ} \mathrm{C}$, but the actual temperature change may be as low as $0.18^{\circ} \mathrm{C}$. In the scenarios such as heating and drying industries, where human interaction with the very high power microwaves is possible, it is crucial to analyze thermal change using TWMBT since the temperature predicted with higher relaxation time may be significantly lower than by Pennes' BTE. Thus, it becomes even more important at higher powers to include relaxation times in temperature analysis to predict the thermal damage, because the actual temperature may be much smaller than projected by conventional method.

The dependence of estimated temperature with different relaxation times on user age is also examined in this study. The temperature changes in a 5 years old child's head due to $900 \mathrm{MHz}$ microwave exposure at $1 \mathrm{~W}$ are numerically investigated. The child's head is modeled by linearly scaling the adult's head in $\mathrm{x}$-axis by a factor of 0.693 [35]. The dielectric properties of child's head (Table 3) are obtained by averaging the dielectric properties of 3 years and 7 years old children from [35]. The thermal properties of child's head are same as that of adult's head. 


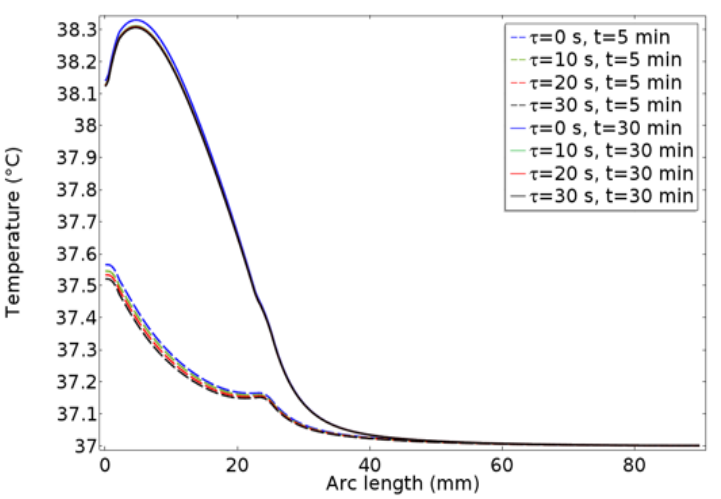

a)

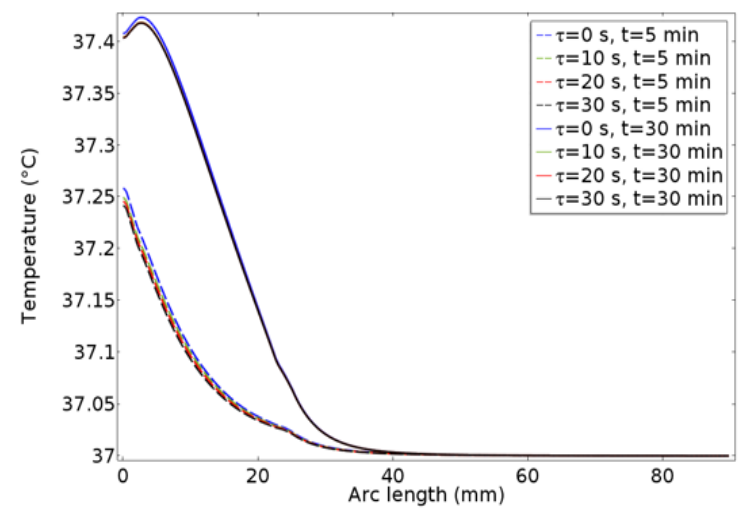

c)

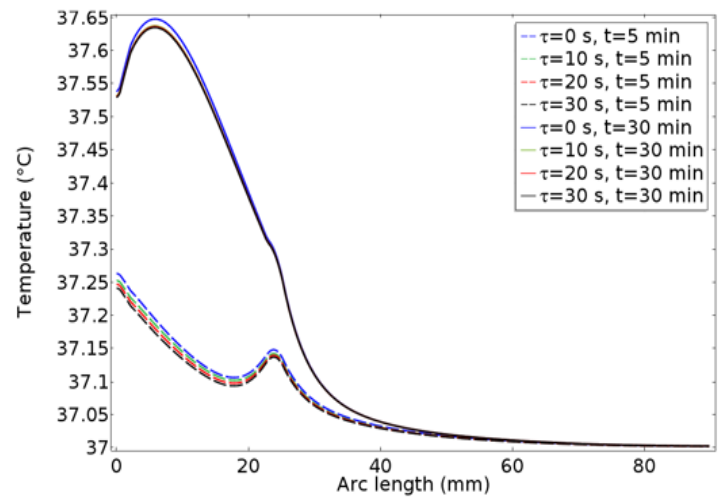

b)

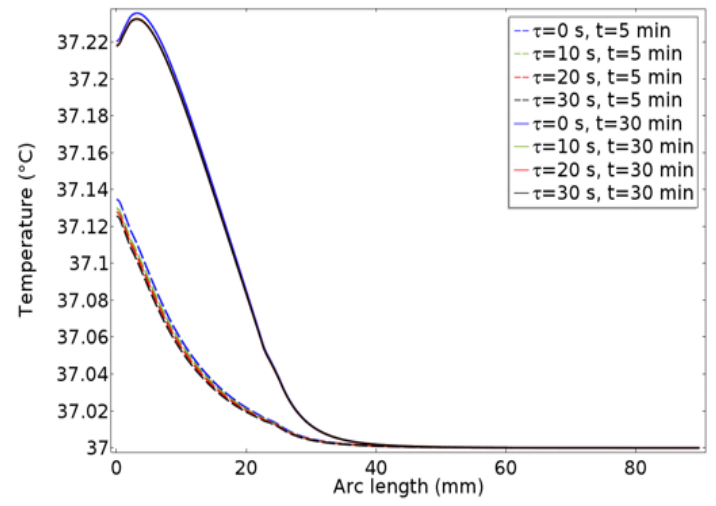

d)

Figure 7. Temperature versus arc length at 5 minutes and 30 minutes of microwave exposure at different frequencies a) $300 \mathrm{MHz}$, b) $900 \mathrm{MHz}$, c) $1800 \mathrm{MHz}$, and d) $2450 \mathrm{MHz}$

Fig. 9 shows the temperature in child's head at 1 minute of microwave exposure at $900 \mathrm{MHz}$ for different relaxation times. Owing to different dielectric properties, the temperature curves for child's head are slightly different than that for adult's head. Brain temperature in child's head is higher than in adult's head which implies greater penetration of microwaves in child's head. The maximum temperature predicted in all the head layers by TWMBT with $\tau=10 \mathrm{~s}$ is $12-17 \%$ lower than that by Pennes' BTE. The temperature curves for $\tau=20 \mathrm{~s}$ and $30 \mathrm{~s}$, estimate temperature 22- 29\% and 31-40\% lower than temperature predicted by Pennes' BTE, respectively.

Fig. 10 compares the temperatures in head layers of the child with that of adult for different values of relaxation time at 1 minute of exposure. For all the values of relaxation time, the temperature change predicted in skin layer of child's head is almost $100 \%$ more than that in adult's skin layer. In fat, bone, CSF, dura and brain layer of child's head the maximum temperatures estimated with all relaxation times are almost 225\%, 325\%, 300\%, $230 \%$, and $310 \%$ higher than that in adult's head, respectively. This conveys that microwave exposure affects the children to a much greater extent than adults. Different dielectric properties of child's tissue than adult's tissues may be held responsible for greater heat generation in child's head. It is also evident from fig. 10 that the temperature changes estimated with different relaxation times show the similar pattern for adult and child's head. Therefore, head temperature predicted using TWMBT with different relaxation times in children is different than that predicted in adults due to altered dielectric properties. 


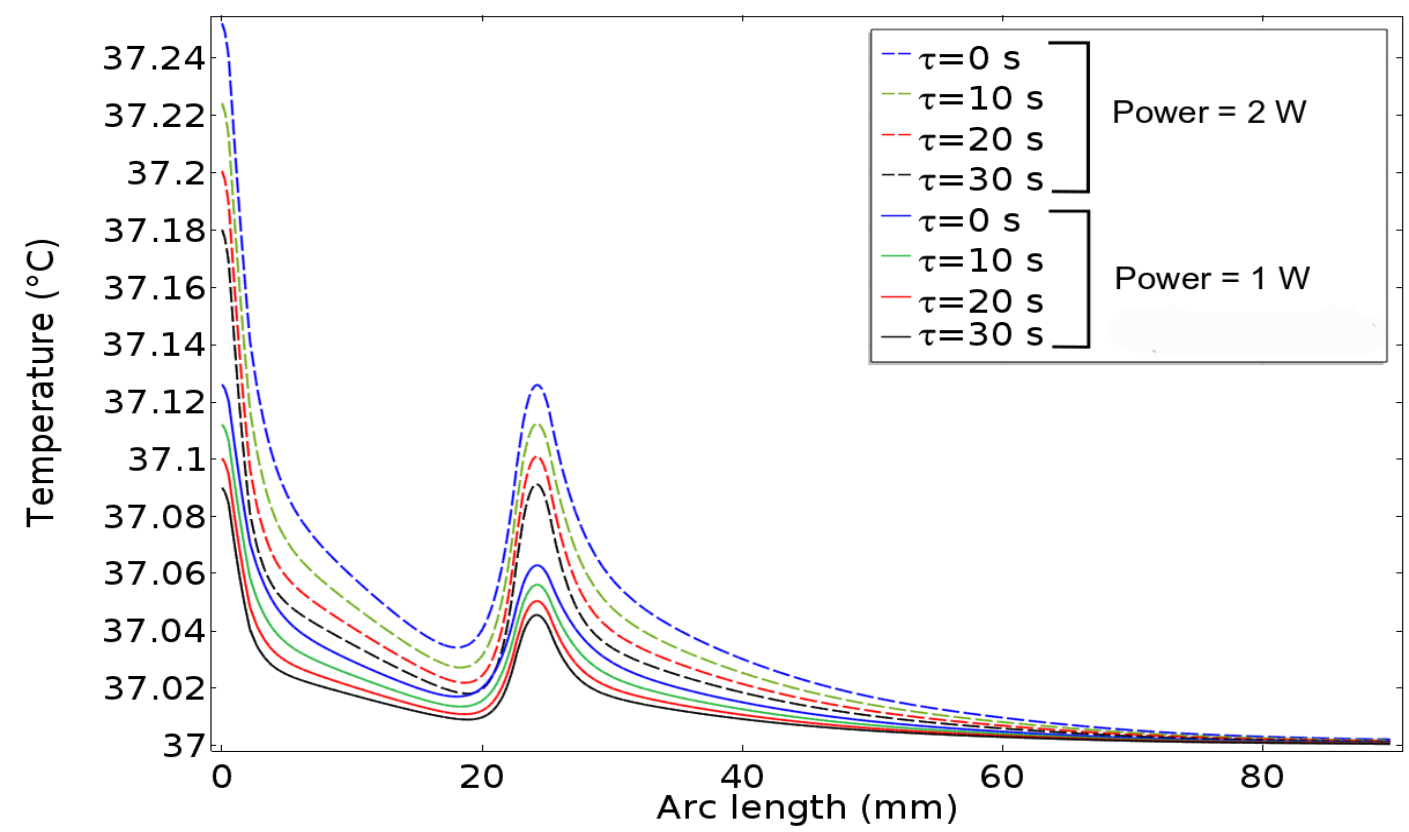

Figure 8. Temperature variations at 1 minute of exposure versus arc length for power $1 \mathrm{~W}$ and $2 \mathrm{~W}$ at $900 \mathrm{MHz}$

Table 3. Dielectric properties of 5 years old child's head at $900 \mathrm{MHz}$ [35]

\begin{tabular}{|c|c|c|}
\hline & Permittivity, $\varepsilon_{\mathrm{r}}$ & Conductivity, $\sigma(\mathrm{S} / \mathrm{m})$ \\
\hline Skin & 42.97 & 0.9 \\
\hline Fat & 12.775 & 0.125 \\
\hline Bone & 22.545 & 0.37 \\
\hline Dura & 45.905 & 0.99 \\
\hline CSF & 35.765 & 2.425 \\
\hline Brain & 47.2 & 0.7875 \\
\hline
\end{tabular}

\section{CONCLUSIONS}

Pennes' BTE is conventionally employed to project the thermal changes in the biological tissues exposed to EM fields. Pennes' BTE assumes that the thermal wave propagates with infinite speed inside the tissue, and it doesn't take account of relaxation times. On the other hand, TWMBT incorporates relaxation times to account for finite speed of heat propagation in biological medium. The present study investigates the effect of relaxation times on the heat transfer within human head exposed to microwaves and compares temperatures predicted by TWMBT with that by Pennes' BTE. A two-dimensional six layers model of human head is exposed to plane microwaves at different frequencies viz. $300 \mathrm{MHz}, 900 \mathrm{MHz}, 1800 \mathrm{MHz}$ and $2450 \mathrm{MHz}$. 


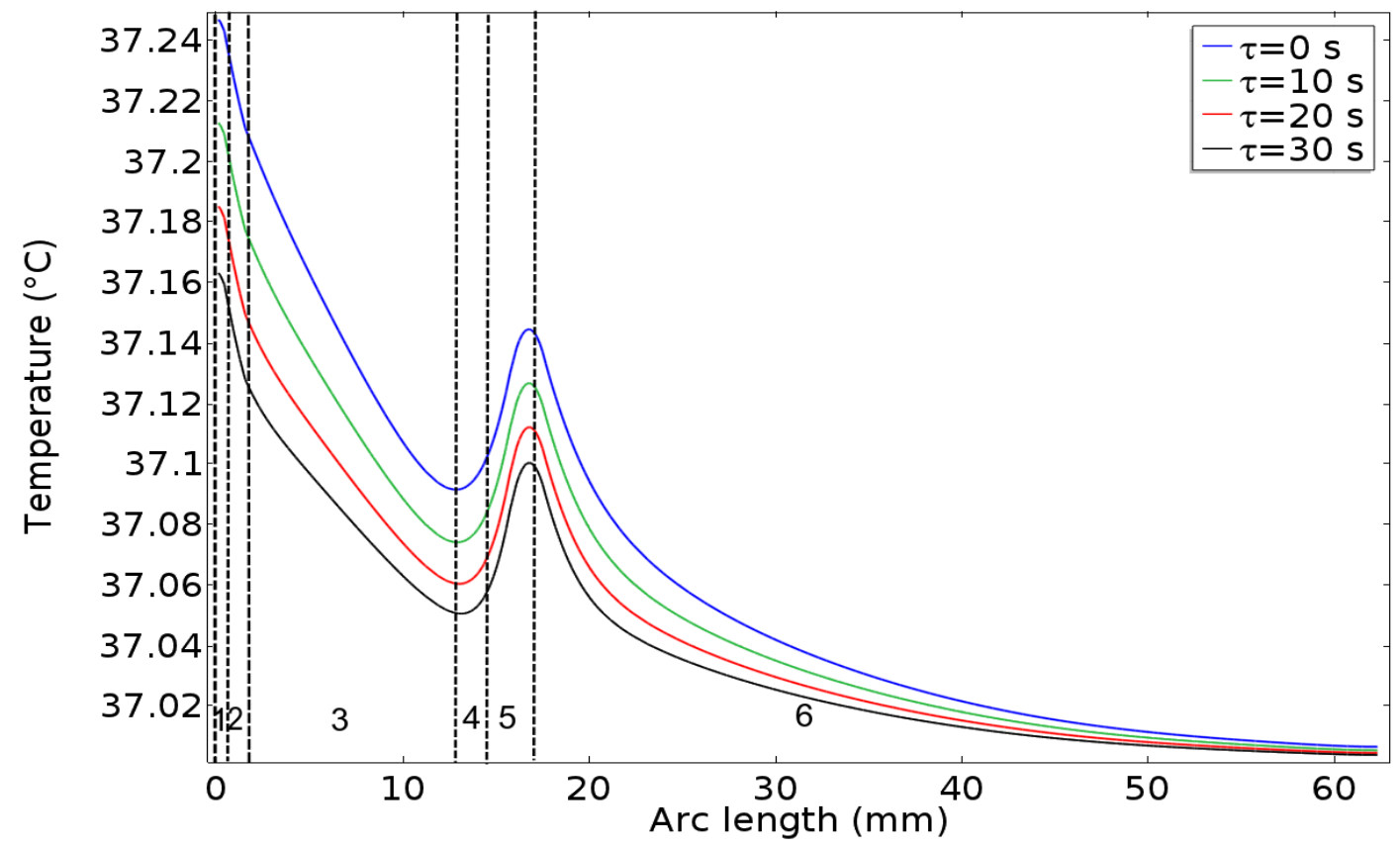

Figure 9. Temperature variations versus arc length in 5 years old child's head at 1 min of exposure. 1: skin, 2: fat, 3: bone, 4: dura, 5: CSF, 6: brain

The analysis shows that highest temperature within the head is predicted with $\tau=0 \mathrm{~s}$, which is identical to temperature predicted by Pennes' BTE. As the relaxation time increases, the predicted temperature lowers. The results show that the temperature estimated with $\tau=10 \mathrm{~s}, \tau=20 \mathrm{~s}$, and $\tau=30 \mathrm{~s}$ can be up to $36 \%, 54 \%$, and $66 \%$ lower than predicted by Pennes' BTE, respectively. This implies that actual temperature change in human head due to exposure may be significantly lower than predicted conventionally. Therefore, it is important to include relaxation times in temperature analysis to predict thermal injury due to microwave exposure.

The study also conveys that the role of relaxation times on temperature variations are significant only if the duration of exposure is short; at longer durations the difference in the temperatures predicted by Pennes' BTE and TWMBT becomes trivial. This implies that only transient temperatures predicted by both models are different, but the steady state temperatures are identical.

The effects of power of microwaves and the user age on the temperature predicted with different relaxation times are also analyzed. For $900 \mathrm{MHz}$, the microwave power of $2 \mathrm{~W}$ caused the temperature change to be $100 \%$ higher than that at $1 \mathrm{~W}$. At $2 \mathrm{~W}$, the maximum temperature change in skin estimated by Pennes' BTE is $0.251{ }^{\circ} \mathrm{C}$, but the actual peak temperature change may be as low as $0.18^{\circ} \mathrm{C}$. The results show that higher power predicts greater temperature; therefore the difference in temperature variations predicted by Pennes' BTE and TWMBT is more at higher powers. Hence, it is important to include relaxation times in temperature analysis to assess the thermal damage accurately at greater powers. The dielectric properties of the child's head tissues are completely different than that of adult's head. Owing to this attribute, the heat generated in child's head due to microwave exposure is much greater than that in adult's head, however the trend in temperature change with different relaxation times in child's head is similar to that in adult's head. Therefore, the children are more prone to the health risks associated with microwave exposure. 


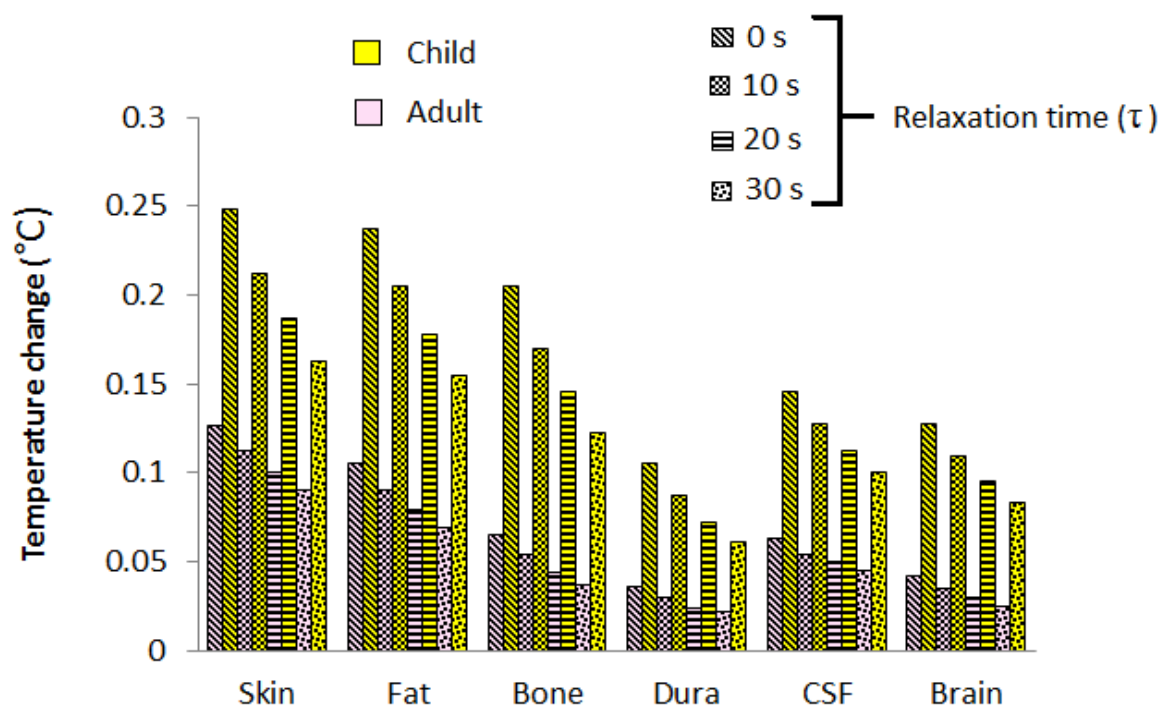

Figure 10. Comparison of temperature changes for different relaxation times in adult and child's head at 1 minute of exposure at $900 \mathrm{MHz}$

This study suggests that for accurate assessment of heat transfer in human head due to microwave exposure, relaxation time should be included in thermal analysis if the duration of the exposure is small and the power of the microwaves is high.

\section{NOMENCLATURE}

C Specific heat capacity at constant pressure, $\mathrm{J} /(\mathrm{kg} . \mathrm{K})$

$\mathrm{C}_{\mathrm{t}} \quad$ Speed of thermal wave, $\mathrm{m} / \mathrm{s}$

E Electric field intensity, $\mathrm{V} / \mathrm{m}$

K Thermal conductivity, W/(m.K)

$\mathrm{k} \quad$ Wave number, $1 / \mathrm{m}$

n Normal vector

Q Heat generation, $\mathrm{W} / \mathrm{m}^{3}$

$\mathrm{T} \quad$ Temperature, ${ }^{\circ} \mathrm{C}$

Greek symbols

$\alpha \quad$ Thermal diffusivity, $\mathrm{m}^{2} \mathrm{~s}^{-1}$

$\varepsilon$ Permittivity, F/m

$\mu \quad$ Magnetic permeability, $\mathrm{H} / \mathrm{m}$

$\rho \quad$ Mass density, $\mathrm{kg} / \mathrm{m}^{3}$

$\tau \quad$ Relaxation time, $s$

$\sigma \quad$ Conductivity of tissue, $\mathrm{S} / \mathrm{m}$

$\omega_{\mathrm{b}} \quad$ Blood perfusion rate, $1 / \mathrm{s}$

$\omega \quad$ Angular frequency, $\mathrm{Hz}$

Subscripts

$0 \quad$ Free space, initial 
Journal of Thermal Engineering, Research Article, Vol. 7, No. 4, pp. 934-950, May, 2021

$\begin{array}{ll}1 & \text { Fundamental } \\ \mathrm{b} & \text { Blood } \\ \mathrm{ext} & \text { External } \\ \mathrm{m} & \text { Metabolic } \\ \mathrm{r} & \text { Relative }\end{array}$

\section{REFERENCES}

[1]. Cleveland Jr. RF. Radio frequency radiation in the environment: sources, exposure standard, and related issue. In: Carpenter DO, Ayrapetyan S, editors. Biological effects of electric and magnetic fields. 1, New York: Academic Press; 1994.

[2]. World Health Organization (WHO) and International Programme on Chemical Safety. Electromagnetic fields $(300 \mathrm{~Hz}$ to $300 \mathrm{GHz}$ )/ published under the joint sponsorship of the United Nations Environment Programme, the International Radiation Protection Association, and the World Health Organization. Geneva: World Health Organization; 1993.

[3]. Ryan KL, D'Andrea JA, Jauchem JR, Mason PA. Radio frequency radiation of millimeter wave length: potential occupational safety issues relating to surface heating. Health Phys 2008; 78(2): 170-81. doi: 10.1097/00004032-200002000-00006

[4]. Durney CH, Massoudi H, Magdy FI. Radio frequency radiation dosimetry handbook. 4th ed. Texas: B rooks Air Force Base; 1986.

[5]. Challis LJ. Mechanisms for interaction between RF fields and biological tissue. Bioelectromagnetics Suppl 2005; 7: S98-S106. https://doi.org/10.1002/bem.20119

[6]. Stuchly MA. Health Effects of Exposure to Electromagnetic Fields. IEEE Aerospace Applications Conference Proceedings 1995; 351-368. doi: 10.1109/AERO.1995.468891

[7]. Adair ER, Adams BW, Akel GM. Minimal changes in hypothalamic temperature accompany microwaveinduced alteration of thermoregulatory behavior. Bioelectromagnetics 1984; 5: 13-30. https://doi.org/10.1002/bem.2250050103

[8]. Kargel C.Infrared Thermal Imaging to Measure Local Temperature Rises Caused by Handheld Mobile Phones. IEEE Trans Instrum Meas 2005; 54: 1513-1519. doi: 10.1109/TIM.2005.851082

[9]. Kodera S, Gomez-Tames J, Hirata A. Temperature elevation in the human brain and skin with thermoregulation during exposure to RF energy. Biomed Eng OnLine 2018; 17:1. https://doi.org/10.1186/s12938-017-0432-x

[10]. Ibrahiem A, Dale C, Tabbara W, Wiart J. Analysis of the temperature increase linked to the power induced by RF source. Prog Electromagn Res 2005; 52: 23-46. doi:10.2528/PIER04062501

[11]. Bernardi P, Cavagnaro M, Pisa S, Piuzzi E. Specific absorption rate and temperature increases in the head of a cellular-phone user. IEEE Trans Microw Theory Tech 2000; 48: 1118-1126. doi: 10.1109/22.848494

[12]. Leeuwen GMJV, Lagendijk JJW, Leersum BJAMV, Zwamborn APM, Hornsleth SN, Kotte ANTJ. Calculation of change in brain temperatures due to exposure to a mobile phone. Phys Med Biol 1999; 44: 2367-2379. DOI: 10.1088/0031-9155/44/10/301

[13]. Wang J, Fujiwara O. FDTD computation of temperature rise in the human head for portable telephones. IEEE Trans Microw Theory Tech. 1999; 47: 1528-1534. doi: 10.1109/22.780405

[14]. Wessapan T, Srisawatdhisukul S, Rattanadecho P, (2012). Specific absorption rate and temperature distributions in human head subjected to mobile phone radiation at different frequencies. Int $\mathrm{J}$ Heat Mass Transf 2012; 55: 347-359. doi: 10.4103/ijpvm.IJPVM_70_17

[15]. Liu J, Chen X, Xu LX. New thermal wave aspects on burn evaluation of skin subjected to instantaneous heating. IEEE Trans Biomed Eng 1999; 46: 420- 428. doi: 10.1109/10.752939

[16]. Ozen S, Helhel S, Cerezci O. Heat analysis of biological tissue exposed to microwave by using thermal wave model of bio-heat transfer (TWMBT). Burns 2008; 34: 45-9. doi.org/10.1016/J.BURNS.2007.01.009 
Journal of Thermal Engineering, Research Article, Vol. 7, No. 4, pp. 934-950, May, 2021

[17]. Liu J, Zhang X, Wang C, Lu W, Ren Z. Generalized time delay bioheat equation and preliminary analysis on its wave nature. Chin Sci Bull 1997; 42: 289-292. https://doi.org/10.1007/BF02882462

[18]. Xu F, Lu T, Seffen KA. Dual-phase-lag model of skin bioheat transfer, Proceedings of the 2008 International Conference on BioMedical Engineering and Informatics 2008; 1: 505-511. doi: 10.1109/BMEI.2008.325

[19]. Liu KC, Wang YN, Chen YS. Investigation on the bio-heat transfer with the dual-phase-lag effect. International Journal of Thermal Sciences 2012; 58: 29-35. https://doi.org/10.1016/j.ijthermalsci.2012.02.026

[20]. Ahmadikia H, Fazlali R, Moradi A. Analytical solution of the parabolic and hyperbolic heat transfer equations with constant and transient heat flux conditions on skin tissue. International Communications in Heat and Mass Transfer 2012; 39: 121-130. https://doi.org/10.1016/j.icheatmasstransfer.2011.09.016

[21]. Xu F, Seffen K, Lu T. Non-Fourier analysis of skin biothermomechanics. International Journal of Heat and Mass Transfer 2008; 51: 2237-2259. https://doi.org/10.1016/j.ijheatmasstransfer.2007.10.024

[22]. Mitra K, Kumar S, Vedevarz A, Moallemi MK. Experimental evidence of hyperbolic heat conduction in processed meat. J Heat Transfer 1995; 117: 568-573. https://doi.org/10.1115/1.2822615

[23]. Banerjee A, Ogale A, Das C, Mitra K, Subramanian C. Temperature distribution in different materials due to short pulse laser irradiation. Heat Transfer Eng 2005; 26: 41-49. https://doi.org/10.1080/01457630591003754

[24]. Antaki P. New interpretation of Non-Fourier heat conduction in processed meat. J Heat Transfer 2005; 127(2): 189-193https://doi.org/10.1115/1.1844540

[25]. Xu F, Lu T. Analysis of skin bioheat transfer, in: Introduction to Skin Biothermomechanics and Thermal Pain Berlin, Heidelberg: Springer; 2011. https://doi.org/10.1007/978-3-642-13202-5_4

[26]. Kaur J, Khan S. Thermal changes in Human Abdomen Exposed to Microwaves: A Model Study. Advanced Electromagnetics 2019; 8(3): 64-75. https://doi.org/10.7716/aem.v8i3.1092

[27]. Liu XZ, Zhu Y, Zhang F, Gong XF. Estimation of temperature elevation generated by ultrasonic irradiation in biological tissues using the thermal wave method. Chin Phys B 2013; 22: 024301. doi: 10.1088/16741056/22/2/024301

[28]. Tullius TK, Bayazitoglu Y. Analysis of relaxation times on the human head using the thermal wave model. Int J Heat Mass Transf 2013; 67: 1007-1013. https://doi.org/10.1016/j.ijheatmasstransfer.2013.08.097

[29]. Pennes HH. Analysis of tissue and arterial blood temperature in the resting human forearm. Journal of Applied Physiology 1948; 1: 93-122. https://doi.org/10.1152/jappl.1948.1.2.93

[30]. Kaminski W. Hyperbolic heat conduction equation for materials with a nonhomogeneous inner structure. J Heat Transfer 1990; 112: 555-560. https://doi.org/10.1115/1.2910422

[31]. Herwig H, Beckert K. Fourier versus non-fourier heat conduction in materials with a nonhomogeneous inner structure. J Heat Transfer 1999; 122: 363-365. https://doi.org/10.1115/1.521471

[32]. Kizilova N, Korobov A. (2019). Bioheat equation with Fourier and non-Fourier heat transport laws: applicability to heat transfer in human tissues. Journal of Thermal Engineering 2019; 5(6): 149-161. https://doi.org/10.18186/thermal.653915

[33]. Cattaneo C. A form of heat conduction equation which eliminates the paradox of instantaneous propagation. Comp Rend 1958; 247: 431-433.

[34]. Vernotte P. (1958). Les paradoxes de la theorie continue de l'equation de la chaleur. Comp Rend 1958; 246 : 3154-3155.

[35]. Sabbah AI, Dib NI, Al-Nimr MA. Evaluation of specific absorption rate and temperature elevation in a multilayered human head model exposed to radio frequency radiation using the finite-difference time domain method. IET Microw Antennas Propag 2011; 5: 1073-1080. doi: 10.1049/iet-map.2010.0172

[36]. International Commission on Non-Ionizing Radiation Protection (ICNIRP). Guidelines for Limiting Exposure to Time-Varying Electric, Magnetic and Electromagnetic Fields (up to $300 \mathrm{GHz}$ ). Health Phys 1998; 74: 494522.

[37]. Spiegel RJ. (1984). A review of numerical models for predicting the energy deposition and resultant thermal response of humans exposed to electromagnetic fields. IEEE Transactions on Microwave Theory and Techniques 1984; 32 (8): 730-746. doi: 10.1109/TMTT.1984.1132767 
[38]. Wessapan T, Rattanadecho P. Temperature induced in human organs due to near-field and far-field electromagnetic exposure effects. International Journal of Heat and Mass Transfer 2018; 119: 65-76. https://doi.org/10.1016/j.jiheatmasstransfer.2017.11.088

[39]. Hasgall PA, Di Gennaro F, Baumgartner C, Neufeld E, Lloyd B, Gosselin MC, Payne D, Klingenböck A, Kuster N. IT'IS Database for thermal and electromagnetic parameters of biological tissues, Version 4.0, May 15, 2018. Accessed on February 11, 2019.

[40]. Wessapan T, Rattanadecho P. Specific Absorption Rate and Temperature Increase in Human Eye Subjected to Electromagnetic Fields at 900 MHz. Int J Heat Transf 2012; 134: 091101-1-11. https://doi.org/10.1115/1.4006243

[41]. Shafahi M, and Vafai K. Human Eye Response to Thermal Disturbances. Journal of Heat Transfer 2011; 133 : 011009-1-7. https://doi.org/10.1115/1.4002360

[42]. Zhao Y, Tang L, Rennaker R, Hutchens C, Ibrahim TS. Studies in RF Power Communication, SAR, and Temperature Elevation in Wireless Implantable Neural Interfaces. PLoS ONE 2013; 8(11): e77759. https://doi.org/10.1371/journal.pone.0077759 